\title{
DESARROLLO DE UN MÉTODO COLORIMÉTRICO EN MICROPLACA PARA DETERMINAR LA CINÉTICA DE CRECIMIENTO DE Staphylococcus aureus
}

\author{
Stiefel, S. ${ }^{1} ;$ Gumiy, d. ${ }^{1} ;$ Canalis, M. ${ }^{1} ;$ SiRoski, P. ; \\ Picco, e. ${ }^{1} ;$ Ortega, H. $^{2}$ \& Formentini, e. ${ }^{1}$
}

\begin{abstract}
RESUMEN
La información generada por las curvas de crecimiento bacteriano se utiliza como referencia para evaluar la actividad antibiótica en ensayos de curvas de muerte bacteriana, pero estas pruebas son laboriosas y requieren mucho tiempo. En este estudio se reporta el desarrollo de un método para la construcción de curvas de crecimiento bacteriano en microplacas, basado en la reducción del cloruro de tetrazolio (XTT) por acción de bacterias metabólicamente activas a formazán, un derivado coloreado y soluble en agua. Este compuesto se cuantifica por colorimetría, permitiendo estimar el número de bacterias viables de modo más fácil y rápido que con el procedimiento de recuento de colonias en placa. El método desarrollado se validó y luego se utilizó para construir curvas de crecimiento de seis cepas de Staphylococcus aureus. Los resultados obtenidos indican que la técnica desarrollada es una herramienta confiable para ser utilizada en estudios de cinética de crecimiento bacteriano.

Palabras clave: Cloruro de tetrazolio, Staphylococcus aureus, cinética de crecimiento.
\end{abstract}

Abreviaturas

UFC: unidad formadora de colonia

STE: sistema de transporte de electrones

XTT: cloruro de tetrazolio

1.- Cátedra de Farmacología. Facultad de Ciencias Veterinarias (UNL). Kreder 2805. (3080) Esperanza, provincia de Santa Fe. E-mail: eforment@fcv.unl.edu.ar

2.- Departamento de Ciencias Morfológicas. FCV (UNL)

Manuscrito recibido el 5 de septiembre de 2013 y aceptado para su publicación el 6 de marzo de 2014 . 


\section{SUMMARY}

\section{Development of a colorimetric method in microplate for determining growth kinetics of Staphylococcus aureus.}

The information generated by bacterial growth curves is often used as reference information for the evaluation of the antibiotic activity in assays of time-kill assays, but these tests are laborious and time consuming. In this study we report the development of a method for constructing bacterial growth curves in microplates based on reduction of a tetrazolium salt (XTT) by metabolically active bacteria to a colored water-soluble formazan derivate. This compound can be quantified colorimetrically, allowing estimation of viable bacteria easily and faster than the classical method of serial dilution bacterial count plates. The developed method was validated and then used to construct growth curves of six bacterial strains of Staphylococcus aureus. The results obtained indicate that the technique developed is a reliable tool to be used in the study of the kinetics of bacterial growth.

Key words: Tetrazolium salt, Staphylococcus aureus, growth kinetic.

\author{
Abbreviations \\ CFU: colony forming unit \\ ETS: electron transport system \\ XTT: tetrazolium salt derivate
}

\section{INTRODUCCIÓN}

El estudio de la cinética de desarrollo o crecimiento bacteriano in vitro se basa en la evaluación de la evolución en el tiempo de una población bacteriana en condiciones estandarizadas y la información generada en estos estudios es útil en varios campos de investigación como microbiología, genética, biotecnología y farmacología. En esta última, la cinética de crecimiento bacteriano tiene aplicación en los ensayos in vitro de eficacia de antibióticos mediante ensayos de curvas de muerte bacteriana (Gloede et al., 2009) en donde se evalúa el efecto in vitro de concen-traciones constantes de fármacos antibac-terianos sobre un número conocido de bacte-rias. En estos ensayos es necesario caracterizar el crecimiento bacteriano en ausencia de antibiótico, a fin de obtener información de referencia para comparar el número de bacterias viables que se obtuvie- ron en ausencia (crecimiento) y en presencia de diferentes concentraciones del mismo (Firsov, 2012; Giacomino et al., 2012a). Esta información permite analizar los resultados con modelos matemáticos para estimar la constante de velocidad de creci-miento bacteriano y de esa manera incorporar este parámetro a modelos farmacocinéticosfarmacodinámicos (PK-PD) para simular la actividad de los antibióticos en condiciones similares a las que se presentan en los focos infecciosos en un organismo viviente (Mueller at al., 2004, Treyaprasert et al., 2007; Li et al., 2008; Giacomino et al., 2012a).

Las curvas de crecimiento bacteriano en ausencia de antibiótico, también han sido utilizadas por nuestro grupo de trabajo para evaluar la actividad bactericida intrínseca de fluidos biológicos tales como suero y orina de canino sobre E. coli (Giacomino et al., 2012a; Giacomino et al., 2012b), suero bovino sobre $S$. aureus y E. coli (Giacomino 